\title{
Failure Analysis and Protection of Oxygen Corrosion of Reheater Tube in a Power plant
}

\author{
Chao Yang ${ }^{1}$, Xiuneng $\mathrm{Li}^{2, *}$, Yunan Wang ${ }^{1}$, and Mingcheng Sun ${ }^{3}$ \\ ${ }^{1}$ Liaoning Dongke Electric Power Co. Ltd, Shenyang, China \\ ${ }^{2}$ China Special Equipment Inspection and Research Institute, Beijing, China \\ ${ }^{3}$ Electric Power Research Institute of State Grid Liaoning Electric Power Co. Ltd, Shenyang, China
}

\begin{abstract}
The failure analysis of reheater tubes were analyzed by means of alloy composition analysis, metallographic structure analysis, mechanical properties analysis and oxide composition analysis. The results showed: The alloy composition meets the requirements of $12 \mathrm{Cr} 1 \mathrm{MoV}$ standard. No abnormality was observed in metallographic structure. Mechanical properties qualified. Oxide components are mainly $\mathrm{O}$ and Fe. Comprehensive analysis shows that The main reason of reheater tube failure is oxygen corrosion, which caused thinning of the reheater tube wall, leading to leakage accident. Suggestions for subsequent protection are put forward.
\end{abstract}

\section{Introduction}

The essence of oxygen corrosion is that the corrosion of iron by dissolved oxygen in water is a kind of electrochemical corrosion. Iron and oxygen form a corrosion battery. The electrode potential of iron is always lower than the electrode potential of oxygen. Therefore, in a ferrite corrosion battery, iron is the anode and is corroded. Dissolved oxygen here acts as a cathode depolarization, which is a factor that causes iron corrosion. It is called oxygen corrosion ${ }^{[1-3]}$. Oxygen corrosion is a typical ulcer corrosion ${ }^{[4,5]}$. The diameter of the corroded area is as small as one millimeter and as large as tens of millimeters. The damage of oxygen corrosion to equipment and pipelines is often not discovered in a short period of time. Oxygen corrosion makes the wall of the boiler drum, convection tube bundle, water wall and other pipes thinner and perforated ${ }^{[6]}$, resulting in a serious shortening of the service life of the boiler and threatening the safe operation of the boiler. On the other hand, the corrosion product iron oxide powder enters the steam turbine part with steam. It is adhered to the nozzles and blades of the steam turbine, so that the steam cannot perform work according to the original design conditions. The efficiency of the steam turbine is affected, and the steam consumption increases, which is not conducive to safe operation. Therefore, sufficient attention should be paid to the oxygen corrosion that occurs in the operation of power station boilers. A case of oxygen corrosion failure of reheater tubes in a certain power plant will be analyzed, the reasons for the failure will be explored, and corresponding protection suggestions will be given.

A thermal power company found that the inner walls of the inlet pipes of the boiler's multiple wall reheaters were corroded to varying degrees during maintenance. The material of the corroded reheater tube is $12 \mathrm{Cr} 1 \mathrm{MoVG}$, the design specification is $\Phi 50 \times 4 \mathrm{~mm}$, the working temperature of the reheater inlet is $325^{\circ} \mathrm{C}$, the working pressure is $3.8 \mathrm{MPa}$, and the cumulative operating time is 66,000 hours.

\section{Experimental program}

The failure characteristics of reheater tubes were observed by macroscopic morphology, and distinguish its failure types. The alloy composition of reheater tube was analysed by a direct reading spectrometer. then the specific composition of the material can be determined of the reheater pipe. Samples were taken from the failed reheater pipes, after grinding, polishing, and corroding, observe and analyze the morphology of the leaking tube through the LSM700 laser confocal microscope and SEM electron microscope. Use an energy spectrometer (EDS) to determine the elemental composition of the corrosion products.

\section{Experimental research}

\subsection{Macroscopic morphology analysis}

Figure 1 shows the macroscopic morphology of the failed reheater tube after sampling. Figure 1(a) is the macroscopic appearance of the outer wall of the two reheater tubes. The outer wall of the two reheater tubes has no obvious defects such as swelling or deformation, and the outer wall oxide scale is normal. Dissecting and observing the two pipes, it was found that there was no obvious oxide layer or scaling site on the inner walls of

${ }^{*}$ Corresponding author: lixiuneng@csei.org.cn 
the two pipes, but several corrosion pits were observed on the inner walls of the two pipes, as shown in Figure 1(b). The macroscopic morphology of the corrosion pits on the inner wall of the root reheater tube.

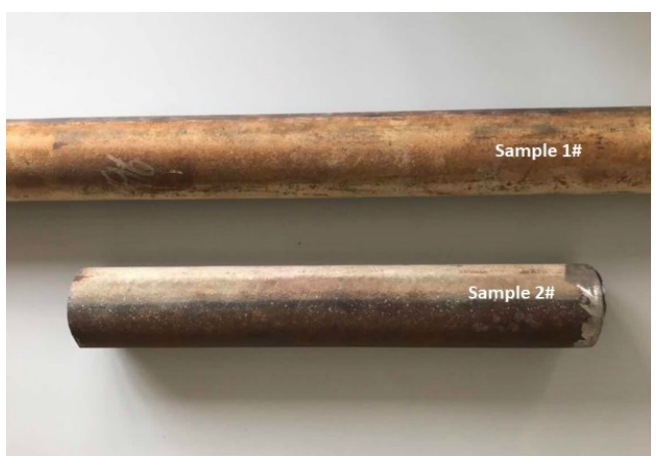

(a) The outer morphology of the tube

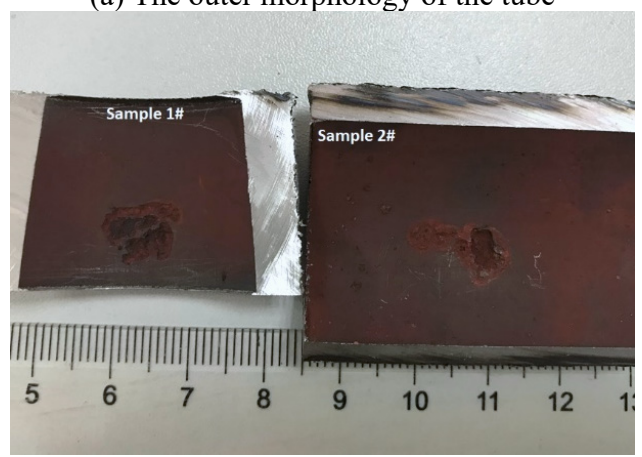

(b) The inner morphology of the tube

Figure 1. Macro morphology of reheater tube

In order to facilitate the observation of the internal morphology and characteristics of the corrosion pits, the two reheater tube corrosion pits were observed with a solid microscope. The morphology is shown in Figure 2. The morphology showed that the corrosion pit of a reheater tube was a stepped ulcer. The corroded surface was covered with reddish brown rust, with a small amount of corrosion products at the bottom, and the texture was relatively loose. The inner wall of the noncorrosive pit is reddish brown and smooth.



(a) $1 \#$ sample

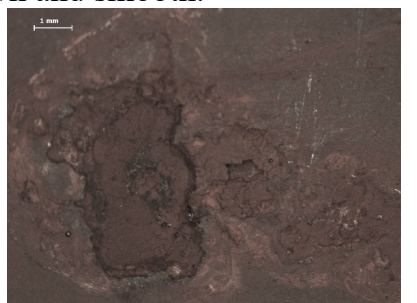

(b) 2\# sample
Figure 2. Macro corrosion morphology of reheater tube

\subsection{Alloy composition analysis}

Take a sample of the reheater tube, flatten it and polish it for chemical composition analysis. The test implementation standard is GB/T 4336-2016, and the instrument model is DV-6 quantitative direct-reading spectrometer. The alloy composition analysis results are shown in Table 1. Table 1 also lists the standard range values of the $12 \mathrm{Cr} 1 \mathrm{MoV}$ steel in GB/T 5310-2017. It can be seen from comparison that the content of the detected elements meets the requirements of the $12 \mathrm{Cr} 1 \mathrm{MoV}$ steel standard.

Table 1 Chemical composition analysis results of reheater tube.

\begin{tabular}{ccccccccc}
\hline $\begin{array}{c}\text { Sample } \\
\text { No. }\end{array}$ & $\mathrm{C}$ & $\mathrm{Si}$ & $\mathrm{Mn}$ & $\mathrm{P}$ & $\mathrm{S}$ & $\mathrm{Cr}$ & $\mathrm{Mo}$ & $\mathrm{V}$ \\
\hline $1 \#$ & 0.10 & 0.20 & 0.55 & 0.010 & 0.004 & 1.01 & 0.26 & 0.20 \\
$2 \#$ & 0.11 & 0.23 & 0.49 & 0.010 & 0.003 & 1.00 & 0.25 & 0.20 \\
& $0.08-$ & $0.17-$ & $0.40-$ & & & $0.90-$ & $0.25-$ & $0.15-$ \\
$12 \mathrm{Cr} 1 \mathrm{MoV}$ & 0.15 & 0.37 & 0.70 & $\leq 0.025$ & $\leq 0.010$ & 1.20 & 0.35 & 0.30 \\
\hline
\end{tabular}

\subsection{Mechanical performance test}

Samples were taken from the two sampling tubes where corrosion did not occur, and the tensile properties were tested at room temperature. The test implementation standard is GB/T 228.1-2010 "Metallic Material Tensile Test Part 1: Room Temperature Test Method". The test equipment model is CMT5205 microcomputercontrolled electronic universal testing machine. The test results are listed in Table 2, and the standard value of the normal temperature tensile performance of $12 \mathrm{Cr} 1 \mathrm{MoVG}$ in GB/T 5310-2017 "seamless steel tubes and pipes for high pressure boiler" is also listed. Compared with the standard reference value, it can be seen that the normal temperature tensile performance values of the two reheater tubes meet the standard requirements.

Table 2. Mechanical properties of reheater tubes.

\begin{tabular}{cccc}
\hline Sample No. & $\begin{array}{c}\mathrm{R}_{\mathrm{m}} \\
\left(\mathrm{N} / \mathrm{mm}^{2}\right)\end{array}$ & $\begin{array}{c}\mathrm{R}_{\mathrm{p} 0.2} \\
\left(\mathrm{~N} / \mathrm{mm}^{2}\right)\end{array}$ & $\mathrm{A}(\%)$ \\
\hline \multirow{2}{*}{$1 \#$} & 530 & 414 & 31 \\
& 527 & 385 & 32 \\
$2 \#$ & 526 & 427 & 31 \\
& 512 & 421 & 28 \\
12Cr1MoV & $470-640$ & $\geq 225$ & $\geq 21$ \\
\hline
\end{tabular}

\subsection{Metallographic analysis}

The metallographic examination was carried out on the cross-sections near the corrosion pits on the inner wall of the 1\# and 2\# samples, as shown in Figure 3-4. The comparison of the metallographic structure of the two reheater tubes reveals that the pits of the two tubes have similar corrosion morphologies, and there is a layer of visible corrosion products at the bottom of the pits. There were no inter-granular or transgranular microcracks, no obvious decarburization layer and aging, as shown in Figure 3(a) and Figure 4(a).

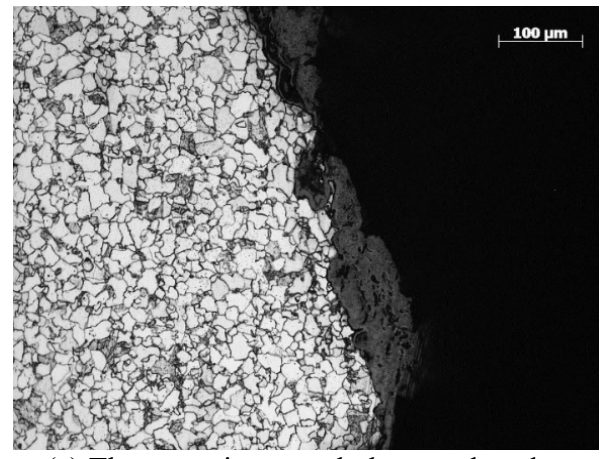

(a) The corrosion morphology at the edge 


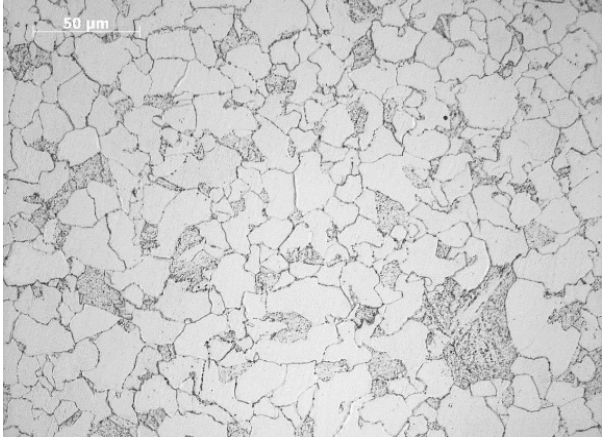

(b) Metallographic structure of matrix

Figure 3. Metallographic structure of reheater tube 1\# sample

In addition, there is no obvious difference between the metallographic structure near the corrosion pit of the reheater tube and the metallographic structure of the matrix, both of which are ferrite and pearlite, with an aging level of 2.5, as shown in Figure 3(b) and Figure 4(b).

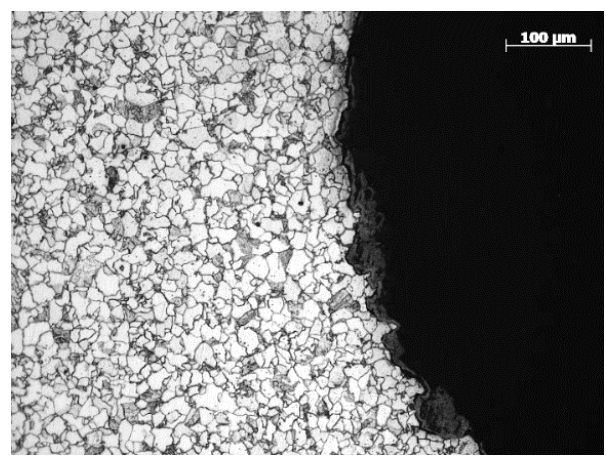

(a) The corrosion morphology at the edge

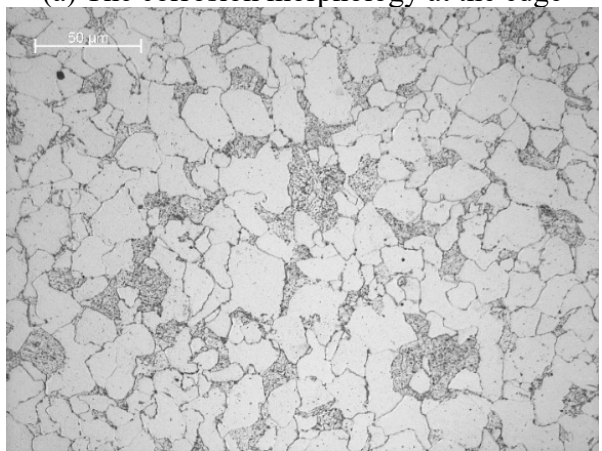

(b) Metallographic structure of matrix

Figure 4. Metallographic structure of reheater tube 2\# sample

\subsection{SEM and EDS analysis}

Figure 5 is the scanning electron microscope (SEM) morphology of the corrosion products at the bottom of the pit of $1 \#$ sample. The topography shows that the oxide structure is loose, with holes, and the surface layer is in the form of fine powder. Except for this, no other foreign matter is seen.

Figure 6 is the energy spectrum of the corrosion product of sample 1\#. According to the peak value, the main elements in the corrosion product are $\mathrm{Fe}$ and $\mathrm{O}$. Comprehensive SEM morphology and EDS results show that the corrosion product of the reheater tube is $\mathrm{Fe}_{2} \mathrm{O}_{3}$.

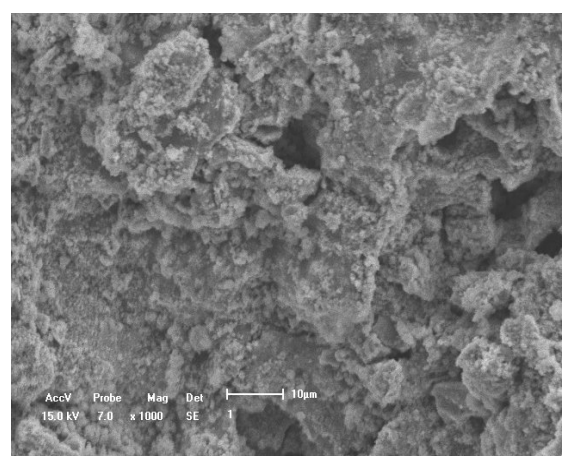

Figure 5 SEM morphology of reheater tube 1\# sample

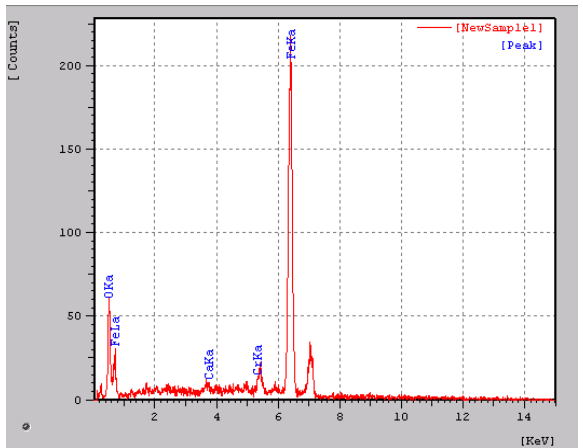

Figure 6. EDS spectrum diagram of reheater tube 1\# sample

\section{Reason analysis and suggestions}

It can be seen from the macroscopic appearance that the outer wall of the reheater tube submitted for inspection is relatively smooth, and there is no trace of oxidation or other loss, but the inner wall of the tube is corroded obviously, and there are many ulcer-like corrosion pits. The surface of the corrosion pit is covered with reddishbrown rust, and the inside of the corrosion product is relatively loose. Macroscopically, the corrosion is caused by the expansion of the inner wall of the tube to the outer wall, and the corrosion gradually penetrates the wall of the tube. The microscopic appearance of the two reheater tubes is similar, and the generation mechanism should be the same. The energy spectrum analysis of the tube matrix shows that the material of the reheater tube is $12 \mathrm{Cr} 1 \mathrm{MoV}$, which meets the requirements of the standard. Observation of the morphology of the reheater tube showed that the metallographic structure of the matrix before the corrosion pit was not abnormal. However, there are discontinuous pits in the corrosion front, and a small amount of corrosion products can be seen inside the pits. In addition, there were no other defects such as decarburized layer or microcracks in the bottom structure. The test results of corrosive substances are mainly $\mathrm{Fe}$ and $\mathrm{O}$. Based on the above test results, the corrosion characteristics of the failure of the reheater tube are consistent with the oxygen corrosion characteristics $^{[4,6]}$.

In addition, when observing the on-site environment of the wall reheater tube, it was found that there was water in the tube during the maintenance of the horizontal section. It shows that the vacuum of the system during the shutdown period did not achieve the 
expected effect. As a result, wet steam remains in the reheater tube, which condenses into water after cooling. On the other hand, it also shows that air has leaked in, creating a humid environment. As a result, the oxygen content in the tube is much higher than the requirements of the working conditions, which provides sufficient conditions for oxygen corrosion of the reheater tube ${ }^{[7]}$.

The oxygen corrosion mechanism is as follows:

On the one hand, because oxygen is a strong cathode depolarizer, it can absorb electrons from the cathode to form hydroxide ions. This intensifies the corrosion process, destroys part of the iron oxide protective film, and leaks the metal on the inner wall. When the internal metal leaks, it will form a local battery with the oxygencontaining aqueous solution, causing iron to precipitate iron ions $\mathrm{Fe}^{2+}$ from the anode. The eluted iron ions $\mathrm{Fe}^{2+}$ and $\mathrm{OH}^{-}$ions form iron hydroxide. $\mathrm{Fe}(\mathrm{OH})_{2}$ is hardly soluble in water and adheres to the metal surface after precipitation.

On the other hand, corrosion products accumulate on the anode in the form of a precipitate, which will inevitably cause a concentration difference between the oxygen concentration in the precipitate and the oxygen concentration in the water covering the surface of the cathode, resulting in an oxygen concentration difference galvanic cell. With the continuous precipitation of $\mathrm{Fe}(\mathrm{OH})_{2}$, the concentration of iron divalent ions in the liquid layer at the anode is significantly reduced, prompting the iron ions on the anode to continue to be transferred into the aqueous solution, that is, the iron as the anode part is quickly dissolved, thereby triggering reThe inner wall of the heat exchanger tube accelerates corrosion.

Thirdly, because $\mathrm{Fe}(\mathrm{OH})_{2}$ is easy to oxidize, it will be further oxidized by $\mathrm{O}$ in water to form $\mathrm{Fe}(\mathrm{OH})_{3}$. Iron hydroxide is insoluble in water and precipitates. The precipitated $\mathrm{Fe}(\mathrm{OH})_{2}$ and $\mathrm{Fe}(\mathrm{OH})_{3}$ are unstable, and a chemical reaction occurs to form stable $\mathrm{Fe}_{2} \mathrm{O}_{3}$.

The electrochemical reaction equation is as follows:

$$
\begin{aligned}
& \mathrm{Fe} \rightarrow \mathrm{Fe}^{2+}+2 \mathrm{e} \\
& 2 \mathrm{H}_{2} \mathrm{O}+\mathrm{O}_{2}+4 \mathrm{e} \rightarrow 4 \mathrm{OH}^{-} \\
& 2 \mathrm{Fe}+2 \mathrm{H}_{2} \mathrm{O}+\mathrm{O}_{2} \rightarrow 2 \mathrm{Fe}(\mathrm{OH})_{2} \\
& 4 \mathrm{Fe}(\mathrm{OH})_{2}+\mathrm{O}_{2}+2 \mathrm{H}_{2} \mathrm{O} \rightarrow \mathrm{Fe}(\mathrm{OH})_{3} \\
& \mathrm{Fe}(\mathrm{OH})_{2}+2 \mathrm{Fe}(\mathrm{OH})_{3} \rightarrow \mathrm{Fe}_{3} \mathrm{O}_{4}+\mathrm{H}_{2} \mathrm{O}
\end{aligned}
$$

The oxygen corrosion in the boiler is mainly related to the dissolved oxygen content in the water quality and the $\mathrm{pH}$ value of the water quality. The following protective measures should be taken to prevent oxygen corrosion in the boiler:

a) Protective measures should be taken during boiler downtime. Prevent the wet steam in the pipeline from remaining and condense into water after cooling. Prevent air from entering the boiler ${ }^{[8,9]}$.

b) When adding feed water during boiler startup, ensure that the deaerator is working properly, monitoring the oxygen content in the feed water, and preventing oxygen from entering the boiler ${ }^{[10,11]}$.

c) Do a good job of monitoring the water quality and $\mathrm{PH}$ value ${ }^{[12]}$, and adjusting the $\mathrm{PH}$ value to operate within the boiler's required range to prevent impurity ions from entering.

d) Strengthen the inspection of the reheater tube, conduct regular thickness inspection and swelling inspection, and monitor it to avoid unexpected shutdown accidents.

\section{Conclusions}

a) The chemical composition and normal temperature mechanical properties of the reheater tube meet the standard requirements, and there is no abnormality in the metallographic structure.

b) The main reason of reheater tube failure is the electrochemical corrosion of dissolved oxygen on the inner wall. The reason for oxygen corrosion is that the residual steam condenses into water and air into the reheater tube during the shutdown of the boiler, resulting in excess oxygen content. oxygen corrosion rapidly thinned the thickness of the tube wall, which eventually led to leakage of the reheater pipe.

\section{References}

1. Yi DQ, Chen LY, Liu HQ, et al. (2012) Research progress on electrochemical corrosion behaviour of cemented carbide. Cemented Carbide, 29(04): 238253.

2. Zhao HP, Zhao WJ, Zhang XF. (2013) Analysis of Metal Electrochemical Corrosion and Anticorrosion. Chemical Engineering and Equipment, (10): 135136.

3. Shao SH. (2006) Oxygen corrosion, deaeration and shutdown maintenance of boilers. Journal of Hebei Energy Vocational and Technical College, 6(003): 75-77.

4. Chen BH, Wu JF. (2003) The harm of oxygen corrosion to thermal equipment and its prevention. China Equipment Engineering, (04): 29-29.

5. Kim YS, Kim WC, Kim J G. (2019) Bulging rupture and caustic corrosion of a boiler tube in a thermal power plant. Engineering Failure Analysis, 104.

6. Qi LY, Cui HJ. (2012) Oxygen corrosion of boilers and solutions. Chemical Engineering and Equipment. 000(005): 115-116.

7. Jiang D, Hong X, Deng B, et al. (2016) Effect of oxygenated treatment on corrosion of the whole steam-water system in supercritical power plant. Applied Thermal Engineering, 93:1248-1253.

8. Chen JG, Liang F. (1992) The failure of boiler and furnace tube and the prevention and control measures. Thermal Power Generation, 000(002):5962. 
9. Sun ZY, Wang WN, Wang JW, et al. (2020) Study on the Mechanism of Oxygen Corrosion of Coalfired Boiler and Protective Measures. China special equipment safety, 36(3): 67-71.

10. Liu JP, Yu JH, Chen WM, et al. (2011) Analysis of boiler shutdown and maintenance based on oxygen corrosion. Henan Science and Technology, 000(003): 62-63.

11. Zou YH, Wang P. (2004) The problem of boiler oxygen corrosion and deaeration methods. Gansu Science and Technology, 020(006): 42-43, 9.

12. Hou PX. (2019) Failure mechanism and prevention of oxygen corrosion in industrial boilers. Popular Standardization, 295(02):24-26. 